\title{
Üniversite Öğrencilerinin Uzaktan Öğretime Yönelik Tutumlarının İncelenmesi: Namık Kemal Üniversitesi Örneği
}

\begin{abstract}
Mehmet Fatih BARIŞ*
Öz

Eğitim, hemen her yaş ve meslek grubundan insanın gündeminde olan bir olgudur. Bilgi ve iletişim teknolojileri ise hem bireylerin hayatında önemli bir yer tutmakta hem de eğitimin şekline, modeline, süresine ve yerine etki etmektedir. Uzaktan öğretim, bilgi ve iletişim teknolojilerinin en üst düzeyde kullanıldığı eğitim şeklidir. Günümüzde birçok eğitim kurumu, şirketler ve kamu kurumları uzaktan öğretimi bir seçenek olarak kullanmaktadır. Üniversiteler, uzaktan öğretim önlisans, lisans, lisansüstü ve sertifika programları açmaktadır. Bazı üniversitelerde ise örgün eğitimi destekleyici bir unsur olarak uzaktan öğretim tercih edilmektedir. Uzaktan öğretim yapan/yapacak kurumların, hedef kitlelerinin uzaktan öğretime yönelik tutumlarının incelenmesi hem kurumun uzaktan öğretim vizyonunun belirlenmesi hem de bu konuda yapılacak çalışmalara kaynaklık etmesi açısından büyük önem arz etmektedir. Bu araştırmada, Namık Kemal Üniversite Tekirdağ Değirmenaltı Yerleşkesinde öğrenim gören öğrencilerinin uzaktan öğretime yönelik tutumlarının farklı değişkenlere göre incelenmesi amaçlanmıştır. Çalışma grubu, 2013-2014 öğretim yılında Namık Kemal Üniversitesi Tekirdağ Değirmenaltı Yerleşkesinde öğrenim gören 2821 . sinıf öğrencisinden oluşmaktadır. Araştırmada Kışla (2005) tarafından geliştirilen “Uzaktan Eğitime Yönelik Tutum Ölçeği" kullanılmıştır. Veriler, Namık Kemal Üniversitesi'nin Öğrenim Yönetim Sistemi (ÖYS) kullanılarak öğrencilere ulaştırılan Google anket aracı ile elde edilmiştir. Niceliksel verilerin karşılaştırılmasında, iki alt düzeyi olan değişkenler için t-testi, ikiden fazla alt düzeyi olan değişkenler için tek yönlü ANOVA ve anlamlı farklılığa neden olan grubun tespitinde Scheffe testi kullanılmıştır. Sonuçta, araştırmaya katılan öğrencilerin tutumlarının genel olarak düşük $(\bar{X}=2,440$; $S S=0,721)$ olduğu saptanmıştır. Cinsiyete göre öğrenci tutumlarında anlamlı bir farklılık gözlenmezken, bilgisayarı olanların, sürekli internet erişim imkanı olanların ve mobil cihazı bulunanların tutum puanlarının, bulunmayanlara göre daha yüksek olduğu gözlenmiştir.
\end{abstract}

Anahtar Kelimeler: Uzaktan öğretim, tutum ölçeği, Namık Kemal Üniversitesi, internet destekli eğitim, uzaktan eğitim tutum ölçeği

\section{Analyzing the University Students' Attitudes Towards Distance Education: Namık Kemal University Case Study}

\begin{abstract}
Education is a fact which is on the agenda of people from almost every age and occupational groups. On the other hand information and communication technologies (ICTs) both have an important place in the lives of individuals and effect style, model, time and place of the education. Distance education is a form of education in which information and communication technologies are used at the highest level. Nowadays, many educational institutions, companies and public institu-
\end{abstract}

*Yrd. Doç. Dr., Namık Kemal Üniversitesi Teknik Bilimler Meslek Yüksek Okulu, mfbaris@nku.edu.tr 
tions are using the distance education as an option. Universities are establishing associate, undergraduate, graduate and certificate programs of distance education. Also, some universities prefer distance education as a supportive factor in formal education. Analyzing the attitudes towards distance education of target groups from institutions which employ or will employ distance education, is greatly important both for defining the distance education vision of the institution and for being the source for the future studies on this subject. This study is aimed at analysing the attitudes towards distance education, of the students who have education at Namı Kemal University Tekirdag Degirmenaltı Campus, according to different variables. The study group consist of 282 freshmen who study at Namik Kemal University Tekirdag Degirmenaltı Campus in 2013-2014. In the study, "The Scale of Attitudes Towards Distance Education " which is developed by Kışla (2005) is used. Data is collected by the Google survey tool which is delivered to the students through the Learning Management System (LMS) of Namik Kemal University. In comparison of the quantitative data, t-test is used to find the difference between two groups, in case of two or more groups, Oneway ANOVA is used to compare the parameters between groups and Scheffe test is used in determination of the group causing difference. In conclusion, the attitude level of the participating students is detected as low $(2,440 \pm 0,721)$. It is observed that the attitude points of those who have computers, continuous internet access possibility and mobile devices, have higher attitude points than those who have none of these, however, based on gender, there is no significant difference observed in the attitudes.

Keywords: Distance education, attitude scale, Namık Kemal University, internet supported education, distance education attitude scale.

\section{GíRiş}

Ortaya çıktığı günden bu yana uzaktan eğitim ile ilgili birçok çalı̧̧ma ve araştırma yapılmıştır. Yapılan çalışmalarda gerek bu eğitim yönteminin etkinliğinin artırılması ve yaygınlaştırılması gerekse gelişen teknolojiye entegre olabilmesi için yapılması gerekenler tartışılmıştır. Bunların yanında uzaktan eğitimin gelişmesi ve yaygınlaşması için uzaktan eğitim yöntemini kullanan, öğreticilerin ve öğrenen bireylerin bu eğitime karşı tutumlarının belirlenmesi de büyük önem arz etmektedir.

Uzaktan eğitim sistemi içerisinde yer alan öğretici, öğrenci, teknik personel, danışman ve yönetici vb. bireylerin uzaktan eğitime yönelik tutum ve düşüncelerinin belirlenmesi konusunda hem yurt içinde hem de yurtdışında birçok çalışma yapılmıştır. Bu çalışmalar uzaktan eğitim yönteminin yönünü ve şeklini belirlemede büyük ölçüde yol gösterici olmuştur.

Smith ve McNeils (1993) yaptıkları araştırmada, öğrencilerin başta uzaktan öğretime yönelik tutumlarının olumsuz olduğunu ancak araş- tırma sonunda öğrencilerin eğitimde teknoloji kullanımını ve uzaktan öğretimi teknolojik bir yöntem olarak benimsediklerini ortaya koymuşlardır. Sankaran ve diğerleri (2000), öğrencilerin web tabanlı öğretime yönelik tutumlarını ve öğrenim çıtılarını araştırmışlardır, sonuçta öğrencilerin tutumları ve öğrenme stratejilerinin eşleştirilmesinin öğrenci başarısını artırdığı görülmüştür. Kazu ve Özdemir (2002), mesleki-teknik öğretim kurumlarındaki öğretmen adaylarının uzaktan eğitim konusundaki görüşlerini belirlemek amacıyla bir araştırma yapmışlardır. Bir başka çalı̧̧mada, Bilgisayar ve Öğretim Teknolojileri Eğitimi Bölümü (BÖTE) 3. ve 4. sınıf öğrencilerinin uzaktan eğitime yönelik tutumları cinsiyet, sınıf düzeyi, uzaktan eğitim alma, bilgisayar kullanma deneyimi, algılanan bilgisayar becerisi ve öğrenme biçemleri açısından incelenmiştir (Ateş ve Altun, 2008). Çalışma sonucunda, uzaktan eğitime yönelik tutumların cinsiyete ve sınıfa göre anlamlı farklılık göstermediği, katılımcıların, daha önce uzaktan eğitim alma durumları, bilgisayar kullanma deneyimleri ve algıladıkları bilgisayar kullanma becerileri uzaktan eğitime yönelik tutumlarını anlamlı ölçüde etkile- 
diği ortaya çıkmıştır. Merisotis ve Phipps (1999), araştırmalarında şu soruların cevaplarını aramışlardır: 1-Uzaktan eğitimin etkinliği ile ilgili bulgular nelerdir? 2- Araştırma sonuçları gelecekte yapılacak çalışmalara işık tutuyor mu? 3- Uzaktan eğitimin geleceği için neler tavsiye edilebilir? Sayılan bu ve benzeri çalışmalar uzaktan eğitimin bugünkü konumuna gelmesinde büyük rol oynamıştır. Yapılan çalışma ve araştırmaların sonucunda sunulan önerilerin, uzaktan eğitimin günümüzdeki halini almasında büyük katkısı olmuştur.

2012 yılında yapılan bir araştırmada, yükseköğretime yeni başlayan öğrenciler ile başlamak üzere olan ortaöğretim son sınıf öğrencilerinin açık ve uzaktan öğrenmeye ilişkin istekli olma durumlarının ve bakış açılarının incelendiği bir anket çalışmasının sonuçları paylaşılmıştır Özkul ve Aydın, 2012). Çalışma sonucunda, öğrencilerin yarısının harmanlanmış öğrenmeyi, yüz yüzeye ve tamamen açık ve uzaktan öğrenmeye göre tercih ettikleri; üçte birden fazlasının açı ve uzaktan öğrenmeye ilişkin yeterince bilgi sahibi olmadıkları saptanmıştır.

2014 yılında yapılan bir çalışmada, uzaktan eğitim yöntemi ile öğrenim görmekte olan bireylerin uzaktan eğitime yönelik görüşlerini ortaya çıkaran bir ölçek geliştirilmiştir. Yıldırım ve arkadaşlarının (2014) yaptıkları çalışma sonucunda, uzaktan eğitimle öğrenim görmekte olan bireylerin bu ortamlara yönelik görüşlerinin belirlenmesinin, ortamların daha etkili tasarlanması ve gerekli müdahalelerin yapılmasında hususunda oldukça önemli olduğu ortaya çıkmıştır. Yine bir başka ölçek geliştirme çalışması Haznedar ve Baran (2012) tarafından gerçekleştirilmiştir. Bu bağlamda eğitim fakültesinde öğrenim görmekte olan üniversite öğrencilerinin e-öğrenmeye yönelik tutumlarını belirlemek için genel bir tutum ölçeği geliştirilmiştir. Özyurt (2014), yaptığı çalışmada uzaktan eğitim bilgisayar programcilı̆̆ı bölümü öğrencilerinin uzaktan eğitime yönelik tutumlarını incelemiştir, araştırma sonucunda öğrencilerin uzaktan eğitime yönelik tutumları 3 grupta toplandığı görülmüştür. A grubu uzaktan eğitimin öğrenmeye olumlu etkileri, B gurubu uzaktan eğitimin yeri ve önemi, uzaktan eğitimin verimsizliği ve güvensizliğidir. Biriş̧̧i (2013) ise video konferans tabanlı uzaktan eğitim etkinlikleri ile öğrenim görmekte olan öğrencilerin uzaktan eğitime yönelik tutum ve görüşlerini araştırmıştır. Uygulamanın sonunda öğrenciler, alana yönelik farklı öğreticilerle tanışma imkanına sahip olunmasını video konferans tabanlı uzaktan eğitim sisteminin olumlu bir özelliği olarak nitelendirmiştir. Video konferans sisteminde yaşanan teknik problemler ve ders anlatımları sürecinde öğretici-öğrenci arasında yüzyüze iletişim kurulmaması da öğrencilerin olumsuz görüşleri olarak ortaya çıkmıştır.

Araştırmanın amacı Namık Kemal Üniversitesi'nde öğrenim gören öğrencilerin uzaktan öğretime yönelik tutum düzeylerinin tespit edilmesidir. Ayrıca öğrenci tutumlarının, fakülteye, cinsiyete, kendine ait bilgisayarı olma durumuna, internete sürekli erişim imkanına ve akıllı telefon veya tablet sahipliğine göre değişkenlik gösterip göstermediği incelenmesi amaçlanmıştır.

\section{YÖNTEM}

Araştırma kesitsel tarama modelinde yürütülmüştür (Büyüköztürk, Kılıç Çakmak, Akgün, Karadeniz ve Demirel, 2012). Kesitsel tarama modeli bir durumu, değişkeni, olguyu aydınlatmak için tek bir seferde veri toplayarak durumun fotoğrafını çekmeyi ve bu fotoğrafı inceleyerek durum, değişkenler ve değişkenler arası ilişkileri ortaya çıkarmayı hedeflemektedir. Araştırmanın bağımlı değişkeni uzaktan 
öğretime yönelik tutumdur. Bu çalışmada, bağımsız değişkenler:

- Fakülte türü,

- Cinsiyet,Kendine Ait Bilgisayarı Olma Durumu,

- İnternete Sürekli Erişim İmkânı,

- Akıllı Telefon veya Tablet Bilgisayar Sahipliğidir.

\section{1 Çalışma Grubu}

Çalışma grubu 2013-2014 öğretim yılında Namik Kemal Üniversite Tekirdağ-Değirmenaltı yerleşkesinde öğrenim gören ve ortak zorunlu dersleri (OZD) uzaktan öğretim yolu ile alan öğrencilerden oluşmaktadır. Öğrencilerin tamamına anket daveti gönderilmiş, çalışma anketi yanıtlayan öğrencilerle gerçekleştirilmiştir. $\mathrm{Bu}$ nedenle örneklemin kolay örnekleme yolu ile belirlendiği söylenebilir (Büyüköztürk ve diğ., 2012). Araştırmaya 8 fakülte/yüksekokul/meslek yüksekokulundan toplam 282 öğrenci katılmıştır (Tablo 1). Katılımın en çok Teknik Bilimler Meslek Yüksekokulundan, en az ise Güzel Sanatlar Tasarım ve Mimarlık Fakültesi'nden olduğu görülmektedir.

Tablo 1. Araştırmaya katılan öğrencilerin fakülteye göre dağılım tablosu

\begin{tabular}{lcc}
\hline \multicolumn{1}{c}{ Gruplar } & Frekans(n) & Yüzde (\%) \\
\hline Fen Edebiyat Fakültesi & 26 & 9,2 \\
Güzel Sanatlar Tasarım Ve Mimarlık Fakültesi & 7 & 2,5 \\
İktisadi Ve İdari Bilimler Fakültesi & 36 & 12,8 \\
Sağlık Hizmetleri Meslek Yüksekokulu & 30 & 10,6 \\
Sağlık Yüksekokulu & 26 & 9,2 \\
Teknik Bilimler Meslek Yüksekokulu & 96 & 34,0 \\
Tip Fakültesi & 10 & 3,5 \\
Ziraat Fakültesi & 51 & 18,1 \\
Toplam & 282 & 100,0 \\
\hline
\end{tabular}

Araştırmaya katılan öğrencilerin cinsiyet dağı-

lımına bakıldığında, katılımcıların \%58,5'i

erkek, \% 41,5'i kadındır (Tablo 2).

Tablo 2. Araştırmaya katılan öğrencilerin cinsiyete göre dağılım tablosu

\begin{tabular}{rlcc}
\hline Değişkenler & \multicolumn{1}{c}{ Gruplar } & Frekans(n) & Yüzde (\%) \\
\hline \multirow{3}{*}{ Cinsiyetiniz } & Erkek & 165 & 58,5 \\
& Kadın & 117 & 41,5 \\
& Toplam & 282 & 100,0 \\
\hline
\end{tabular}

\subsection{Veri Toplama Araçları}

Bu çalışmada Kışla (2005) tarafından geliştirilen “Üniversite Öğrencilerinin Uzaktan Eğitime Yönelik Tutum Ölçeği” kullanılmıştır. Ön çalışmada ortaya çıkan 83 maddelik ölçek incelemeler sonucu 36 maddeye indirilmiş ve içerik geçerliliğinin sağlanması amacıyla uzman görüşüne sunulmuştur. Uzman görüşleri sonucu bir madde ölçekten çıkarılmıştır. Uzman görüşleri alındıktan sonra tutum ölçeği ön uygulama için hazır duruma gelmiştir. Ön uygulamada yapı geçerliliğini belirlemek amacıyla faktör analizi yapılmıştır. Ölçeğin faktör analizi, SPSS 11.0 ile üzerinde temel bileşenler analizi kullanılarak gerçekleştirilmiştir. Sonuç olarak ölçekteki tüm maddelerin tek bir faktöre yük verdiği görülmüştür. Faktör analizinden elde edilen bulgular, ölçeğin yapı geçerliliğinin göstergesi olarak yorumlanmıştır. Ölçeğin güvenirliliğinin tespiti için, araştırmacı tarafın- 
dan, Ege Üniversitesi Eğitim Fakültesi BÖTE Bölümü öğrencilerinden rasgele seçilen 121 kişilik bir gruba veri toplama aracı uygulanmış ve güvenirlilik değeri 0,8918 olarak tespit edilmiştir. Yapılan asıl uygulamada ölçeğin güvenirliliğini tekrar sorgulamak için alfa katsayısına bakılmıştır. Alfa katsayısı 0,8976 olarak bulunmuştur. Uygulama sonuçlarına göre ölçeğin güvenirliliğinin yüksek düzeyde olduğu görülmüştür. Ölçekte yer alan 35 adet yarg1 cümlesinin karşısındaki seçeneklerde “(1) Kesinlikle kat1liyorum (2) Katıliyorum (3) Kararsızım (4) Katılmıyorum (5) Kesinlikle katılmıyorum" şeklinde derecelendirme yapılmıştır.

Ölçekte yer alan yargı cümlelerinin karşısındaki seçeneklerde “(1) Kesinlikle katıllyorum (2) Katılıyorum (3) Kararsizım (4) Katılmıyorum (5) Kesinlikle katılmıyorum" şeklinde derecelendirme yapılmıştır.

Ölçeğin 1., 2., 4., 5., 9., 11., 14., 15., 16., 18., 19., 22., 23., 25., 26., 28., 29., 33. ve 34. Maddeleri düz maddelerdir ve en olumlu ifadeye yukarıda belirtildiği gibi 5 puan, en olumsuz ifadeye 1 puan verilecek şekilde puanlanmışlardır.

3., 6., 7., 8, 10., 12., 13., 17., 20., 21., 24., 27., 30., 31., 32. ve 35. maddeler ise ters maddelerdir ve En olumsuz ifadeye 5 puan, en olumlu ifadeye 1 puan verecek şekilde puanlanmışlardır.

Veriler, Namık Kemal Üniversitesi Uzaktan Ĕgitim Merkezi'nce uzaktan öğretimde kullanılan Öğretim Yönetim Sistemi mesaj ve e-posta sistemi aracilığı öğrencilere davetleri ulaştırılan, Google formlar aracilığıyla toplanmıştır.

\subsection{Verilerin Analizi}

Araştırmada elde edilen veriler SPSS (Statistical Package for Social Sciences) for Windows 21.0 programı kullanılarak analiz edilmiştir. Verileri değerlendirilirken tanımlayıcı istatistiksel me- totları (Sayı, Yüzde, Ortalama, Standart sapma) kullanılmıştır.

Niceliksel verilerin karşılaştırılmasında iki grup arasındaki farkı t-testi, ikiden fazla grup durumunda parametrelerin gruplar arası karşılaştırmalarında Tek yönlü (One way) Anova ve farklıllğa neden olan grubun tespitinde Scheffe testi kullanılmıştır. Elde edilen bulgular \%95 güven aralığında, \%5 anlamlılık düzeyinde değerlendirilmiştir.

\subsection{Araştırmanın Sınırlılıkları}

$\mathrm{Bu}$ çalışmanın en önemli sınırlılı̆̆ı, mevcut öğrenci havuzunun ancak \%10 unun çalışmaya dâhil olmasıdır. Ayrıca kolay örnekleme yönteminin kullanılmış olması nedeniyle çalışmaya katılan öğrencilerin bulundukları birimin tüm katılımcı özelliklerini temsil etme gücü belirsizdir. İleride yapılacak araştırmalarda katılım oranının yükseltilmesi için çalışmalar yapılabilir, eposta ve ÖYS haricinde alternatif katılım imkân ve davetleri sunulabilir.

\section{BULGULAR}

Araştırma sonucunda katılımcıların büyük çoğunluğunun kendine ait bilgisayarı olduğu, yarısından fazlasının internete sürekli erişim imkanı bulunduğu ve yine yarısından fazlasının akıllı telefon veya tablet bilgisayar sahibi olduğu görülmüştür. Araştırmaya katılan öğrencilerin uzaktan eğitime yönelik tutum düzeylerinin düşük olduğu, Güzel Sanatlar, Tasarım ve Mimarlık Fakültesi öğrencilerinin tutum puanlarının diğer fakülte veya yüksekokul öğrencilerinin tutum puanlarından yüksek olduğu ortaya çıkmıştır. Araştırma sonucunda elde edilen bulgular detaylı bir şekilde aşağıda listelenmiştir.

1) Öğrencilerin $224 \ddot{u}(\% 79,4)$ kendine ait bilgisayarı olduğunu ifade ederken, 58 i $(\% 20,6)$ 
bilgisayarlarının bulunmadığının ifade etmişlerdir. 175 i $(\% 62,1)$ internete sürekli erişim imkânı olduğunu ifade ederken 107 si $(\% 37,9)$ sürekli internet erişim imkânlarının bulunmadığını belirtmişlerdir. Öğrencilerin 160'ının $(\% 56,7)$ akıllı telefon veya tablet bilgisayarı varken, 122' sinin $(\% 43,3)$ akıllı telefon veya tablet bilgisayarı bulunmadığı görülmüştür (Tablo 3.) Bu bulgular katılımcıların çoğunun akıllı telefonu ya da tablet bilgisayarı olduğunu göstermektedir. Bu durum uzaktan eğitimden mobil olarak yararlanma açısından öğrencilerin

Tablo 3. Öğrencilerin kendine ait bilgisayarı olma durumu, internete sürekli erişim imkânı ve akıllı telefon ve tablet bilgisayar sahipliğine göre dağılımları

\begin{tabular}{llll}
\hline Değişkenler & Gruplar & Frekans(n) & Yüzde (\%) \\
\hline \multirow{2}{*}{ Kendine Ait Bilgisayarı Olma Durumu } & Evet & 224 & 79,4 \\
& Hayır & 58 & 20,6 \\
İnternete Sürekli Erişim İmkânı & Toplam & 282 & 100,0 \\
& Evet & 175 & 62,1 \\
& Hayır & 107 & 37,9 \\
Akıllı Telefon veya Tablet Bilgisayar Sahipliği & Toplam & 282 & 100,0 \\
& Evet & 160 & 56,7 \\
& Hayır & 122 & 43,3 \\
\hline
\end{tabular}

Araştırmada kullanılan likert ölçek kişilerin verilen önermelerle ilgili görüşlerini belirlemesi için çok olumludan çok olumsuza kadar sıralanmıştır. Faktör analizi sonrası ölçek genel puanı veya faktörlerdeki boyutlar hesaplanırken aritmetik ortalama alınır. Ölçek genel pua$\mathrm{n} 1$ ve faktör (boyut) puanları 5.00-1.00=4.00 puanlık bir genişliğe dağılmaktadır. Bu genişlik beşe bölünerek ölçeğin kesim noktalarını belirleyen düzeyler belirlenir. Ölçek ifadelerinin yarısından fazlasının teknolojik olanağa sahip olduğunu göstermektedir. Diğer taraftan azımsanamayacak sayıda öğrencinin uzaktan öğrenmede mobil olarak içeriğe ulaşacak bir teknolojiye sahip olmaması dikkat çekmektedir. Mobil öğrenmelerin uzaktan eğitime katkısı dikkate alındığında daha etkili ve verimli bir uzaktan eğitim için öğrencilere mobil cihazlara sahip olma olanaklarının artırılmasının tutumlarını etkileyebileceği akla gelmektedir.

Tablo 4. Uzaktan Eğitime Yönelik Tutum Düzeyi

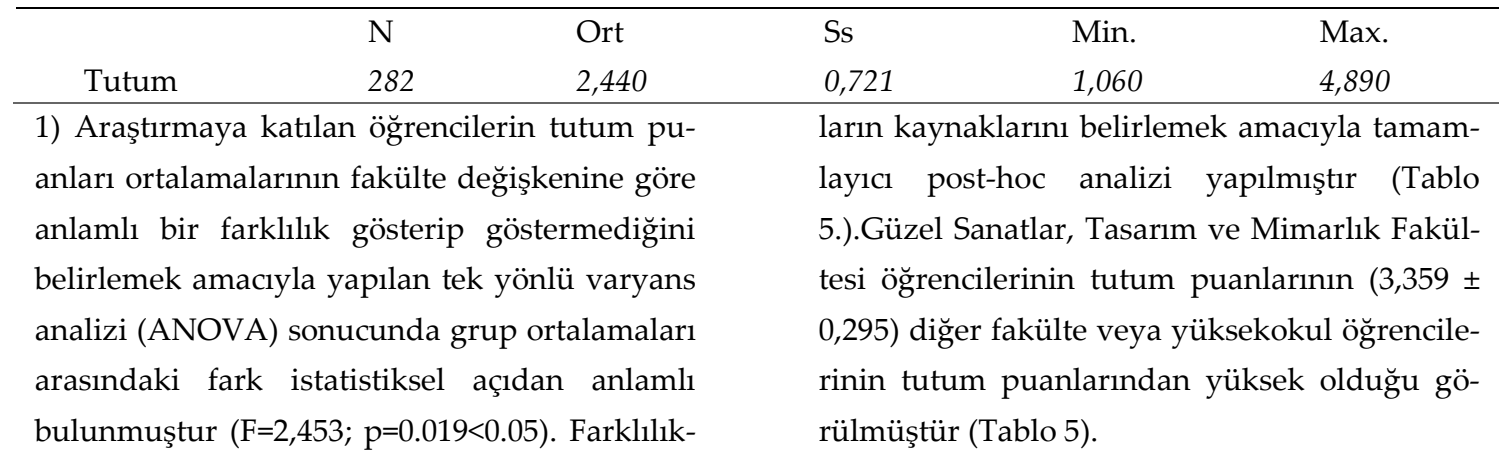


Tablo 5. Uzaktan Eğitime Yönelik Tutum Düzeyinin FakülteyeGöre Ortalamaları

\begin{tabular}{|c|c|c|c|c|c|c|c|}
\hline & Grup & $\mathrm{N}$ & Ort & Ss & $\mathrm{F}$ & $\mathrm{p}$ & Fark \\
\hline & 1- Fen Edebiyat Fakültesi & 26 & 2,439 & 0,557 & 2,453 & 0,019 & $2>1$ \\
\hline & 2 -Güzel Sanatlar, Tasarım Ve Mimarlık & 7 & 3,359 & 0,295 & & & $2>3$ \\
\hline & Fakültesi & & & & & & $2>4$ \\
\hline & 3-İktisadi Ve İdari Bilimler Fakültesi & 36 & 2,446 & 0,891 & & & $2>4$ \\
\hline Tutum & 4-Sağlık Hizmetleri Meslek Yüksekokulu & 30 & 2,251 & 0,744 & & & $2>5$ \\
\hline & 5-Sağlık Yüksekokulu & 26 & 2,300 & 0,602 & & & $2>6$ \\
\hline & 6-Teknik Bilimler Meslek Yüksekokulu & 96 & 2,398 & 0,727 & & & $2>7$ \\
\hline & 7-Tıp Fakültesi & 10 & 2,429 & 0,259 & & & $2>8$ \\
\hline & 8 -Ziraat Fakültesi & 51 & 2,575 & 0,711 & & & \\
\hline $\begin{array}{l}\text { 2) Araş } \\
\text { anları } \\
\text { göre ar } \\
\text { diğini b } \\
\text { cunda \& }\end{array}$ & $\begin{array}{l}\text { rmaya katılan öğrencilerin tutum pu- } \\
\text { talamalarının "Cinsiyet" değişkenine } \\
\text { amlı bir farklılık gösterip gösterme- } \\
\text { lirlemek amacıyla yapılan t-testi sonu- } \\
\text { up ortalamaları arasındaki fark istatis- }\end{array}$ & & $\begin{array}{l}43>0,05) \\
\text { ik tutun } \\
\text { memesi } \\
\text { n olmam }\end{array}$ & $\begin{array}{l}\text { (Tablo } \\
\text { ların } \\
\text { bu konı } \\
\text { lası açı }\end{array}$ & $\begin{array}{l}\text { 6). } \mathrm{Uz} \\
\text { nsiyete } \\
\text { da deza } \\
\text { ndan o }\end{array}$ & $\begin{array}{l}\text { ktan } \\
\text { göre } \\
\text { antajlı } \\
\text { imlu }\end{array}$ & $\begin{array}{l}\text { ğitime } \\
\text { arklilık } \\
\text { ir du- } \\
\text { ir bul- }\end{array}$ \\
\hline
\end{tabular}

tiksel açıdan anlamlı bulunmamıştır ( $\mathrm{t}=1,467$;

Tablo 6. Uzaktan Eğitime Yönelik Tutum Düzeyinin Cinsiyete Göre Ortalamaları

\begin{tabular}{ccccccc}
\hline & Grup & N & Ort & Ss & t & p \\
\hline \multirow{2}{*}{ Tutum } & Erkek & 165 & 2,493 & 0,766 & 1,467 & 0,143 \\
& Kadın & 117 & 2,365 & 0,646 & & \\
\hline
\end{tabular}

3) Araştırmaya katılan öğrencilerin tutum puanları ortalamalarının "Kendine ait bilgisayar olma" değişkenine göre anlamlı bir farklılık gösterip göstermediğini belirlemek amacıyla yapılan t-testi sonucunda grup ortalamaları arasındaki fark istatistiksel açıdan anlamlı bulunmuştur $(t=4,383 ; p=0,000<0,05)$. Kendine ait bilgisayarı olanların tutum puanları $(x=2,533)$, kendine ait bilgisayarı olmayanların tutum puanlarından $(\mathrm{x}=2,082)$ yüksek bulunmuştur (Tablo 7). Birçok araştırmada benzer bulgulara ulaşılmıştır. Bilgisayar sahibi olmanın uzaktan eğitime yönelik tutumu olumlu yönde etkilemesi beklenen bir durumdur. Bireylerin bilgisayar sahibi olması bilgisayara olan aşinalığ 1 artırmakta bu da bilgisayar ve internet konusundaki birçok konuya karşı tutumlarını olumlu yönde etkilemektedir.

Tablo 7. Uzaktan Eğitime Yönelik Tutum düzeyinin kendine ait bilgisayar olma durumu Göre Ortalamaları

\begin{tabular}{ccccccc}
\hline & Grup & $\mathrm{N}$ & Ort & Ss & $\mathrm{t}$ & $\mathrm{p}$ \\
\hline \multirow{3}{*}{ Tutum } & Evet & 224 & 2,533 & 0,714 & 4,383 & 0,000 \\
& Hayır & 58 & 2,082 & 0,635 & & \\
& katr & &
\end{tabular}

4) Araştırmaya katılan ögrencilerin tutum puanları ortalamalarının "İnternete sürekli erişim imkanı bulunma" değişkenine göre anlamlı bir farklılık gösterip göstermediğini belirlemek amaciyla yapilan t-testi sonucunda grup ortalamaları arasındaki fark istatistiksel açıdan anlamlı bulunmuştur ( $\mathrm{t}=3,429 ; \mathrm{p}=0,001<0,05)$. İnternete sürekli erişim imkanı olanların tutum puanları $(x=2,553)$, internete sürekli erişim imkanı olmayanların tutum puanlarından $(x=2,255)$ yüksek bulunmuştur (Tablo 8). Bir önceki bulguda olduğu gibi internete erişim imkanının bulunması da bireylerin internet tabanlı uygulamalara karşı tutumlarını olumlu yönde etkilemektedir. 
Tablo 8.Uzaktan Eğitime Yönelik Tutum düzeyinin internete sürekli erişim imkanına Göre Ortalamaları

\begin{tabular}{ccccccc}
\hline & Grup & $\mathrm{N}$ & Ort & Ss & $\mathrm{t}$ & $\mathrm{p}$ \\
\hline \multirow{2}{*}{ Tutum } & Evet & 175 & 2,553 & 0,731 & 3,429 & 0,001 \\
& Hayır & 107 & 2,255 & 0,667 & & \\
\hline
\end{tabular}

5) Araştırmaya katılan öğrencilerin tutum puanlamlı bulunmuştur $(\mathrm{t}=2,790 ; \mathrm{p}=0,004<0,05)$. anları ortalamalarının "Akıllı telefon veya Akıllı telefon veya tablet sahibi olanların tutum tablet sahipliği” değişkenine göre anlamlı bir farklılık gösterip göstermediğini belirlemek amaciyla yapilan t-testi sonucunda grup ortalamaları arasındaki fark istatistiksel açıdan

Tablo 9. Uzaktan Eğitime Yönelik Tutum düzeyinin akıllı telefon veya tablet sahipliğine Göre Ortalamaları

\begin{tabular}{ccccccc}
\hline & Grup & $\mathrm{N}$ & Ort & Ss & $\mathrm{t}$ & $\mathrm{p}$ \\
\hline \multirow{3}{*}{ Tutum } & Evet & 160 & 2,543 & 0,785 & 2,790 & 0,004 \\
& Hayır & 122 & 2,304 & 0,603 & & \\
\hline
\end{tabular}

\section{SONUÇ ve ÖNERİLER}

Üniversite öğrencilerinin uzaktan eğitime yönelik tutum düzeylerini belirlemek amacıyla yapılan bu çalışmada öğrencilerin yaklaşık \%80 inin kendisine ait bilgisayarı olduğu, \%62 sinin internete sürekli erişim imkânının olduğu ve \%57 sinin akıllı telefon veya tablet bilgisayarı-

Tablo 10. Türkiye Geneli Bilgi Toplumu İstatistikleri, 2010-2014

\begin{tabular}{lccccc}
\hline & 2010 & 2011 & 2012 & 2013 & 2014 \\
\hline Bilgisayar Kullanımı (Toplam) & 43,2 & 46,4 & 48,7 & 49,9 & 53,5 \\
Erkek & 53,4 & 56,1 & 59,0 & 60,2 & 62,7 \\
Kadın & 33,2 & 36,9 & 38,5 & 39,8 & 44,3 \\
İnternet Kullanımı (Toplam) & 41,6 & 45,0 & 47,4 & 48,9 & 53,8 \\
Erkek & 51,8 & 54,9 & 58,1 & 59,3 & 63,5 \\
Kadın & 31,7 & 35,3 & 37,0 & 38,7 & 44,1 \\
Hanelerde İnternet erişimi & 41,6 & 42,9 & 47,2 & 49,1 & 60,2 \\
\hline
\end{tabular}

Araştırmaya katılan öğrencilerin uzaktan eğitime yönelik tutum düzeylerinin düşük olduğu görülmüştür. Öğrencilerin bilgisayar sahibi olma oranı \%80 civarında, akıllı telefon veya tablet bilgisayar sahiplik oranı \%57 civarında ve \%62 sinin internete sürekli erişim imkânı bulunmasına rağmen uzaktan eğitime yönelik tutum düzeylerinin düşük çıkması bu öğrencilerin önceki dönemlerde internet ve bilgisayarı eğitim amaçlı kullanmadığının göstergesi olabi- nın bulunduğu görülmüştür. Bu oranlar, Türkiye İstatistik Kurumu'nun (TÜİK) yaptığı bireylerin bilişim teknolojileri kullanımına yönelik araştırmalarda çıkan oranların üzerindedir (Tablo 10).

lir. Öğrencilerin uzaktan eğitime yönelik tutum düzeylerinin düşük olmasının bir diğer sebebi de eğitim modeline sıcak bakmamalarından kaynaklanıyor olabilir. Benzer bir çalışma sonucunda (Özkul ve Aydın, 2012), öğrencilerin yarısının harmanlanmış öğrenmeyi, yüz yüzeye ve tamamen açık ve uzaktan öğrenmeye göre tercih ettikleri tespit edilmiştir. Powers ve Mitchell (1997) web tabanlı bir kurs yapmış, bu çalışmada öğrenciler interneti zaman alıcı bul- 
muş ve sınıf ortamındaki ruhu elde edememekten şikayet etmişlerdir. İnternet üzerinden gruplar kurarak bu eksikliği gidermeye çalışmış ancak çalışma sonunda öğrencilerin öğrenme performansları yönünden olumsuz tutum sergiledikleri görülmüştür.

Öğrencilerin öğrenim gördükleri birime göre uzaktan eğitime yönelik tutumlarında farklılık olup olmadığını belirlemek için yapılan analizler sonucunda anlamlı farklılıklar olduğu görülmüştür. Güzel Sanatlar, Tasarım ve Mimarlık Fakültesi öğrencilerinin uzaktan eğitime yönelik tutum düzeyleri diğer tüm fakülte, yüksekokul ve meslek yüksekokullarından oldukça yüksek çıkmıştır. Bu sonuç, çalışmaya katılan öğrencilerin bilgisayar ve internet okuryazarlık düzeylerinin yüksek olmasından kaynaklanıyor olabilir. Eğitim görülen birime göre bakıldığında diğer dikkat çeken bir husus da fakülte öğrencilerinin uzaktan eğitime yönelik tutum düzeylerinin yüksekokul ve meslek yüksekokulu öğrencilerine göre daha yüksek olduğudur. Bu sonuçların bir başka nedeni ise araştırma örnekleme yönteminin kolay örnekleme olması nedeniyle araştırmaya katılan öğrencilerin okudukları fakülteyi temsil etme güçlerinin belirsiz olmasıdır. İleride yapılacak araştırmalarda temsil gücü yüksek örneklemlerden toplanacak verilerle fakülte karşılaştırmasına yönelik bu sonuçlar doğrulanmalıdır.

Ataş ve Altun'un (2008) yaptı̆̆ çalışmanın sonucunda, öğrencilerin uzaktan eğitime yönelik tutum düzeylerinin cinsiyete ve sınıfa göre anlamlı farklılık göstermediği ortaya çıkmıştır. $\mathrm{Bu}$ çalışmada da benzer bir sonuç çıkmış, öğrencilerin tutum puanlarının "Cinsiyet" değiş- kenine göre grup ortalamaları arasındaki fark istatistiksel açıdan anlamlı bulunmamıştır.

Bilişim teknolojilerine sahiplik yönünden bakıldığında daha önce yapılan çalışmalarda çıkan sonuçlara benzer sonuçlar ortaya çıktığı görülmüştür. Buna göre; bilgisayarı olan öğrencilerin olmayanlara göre daha olumlu tutum sergiledikleri, internete sürekli erişim imkânı olanların olmayanlara göre daha olumlu tutum sergiledikleri, akıllı telefon ve tablet bilgisayarı olan öğrencilerin olmayanlara göre daha olumlu tutumlarının olduğu görülmüştür.

Uzaktan eğitim yaygınlaştıkça bu konuda yapılacak çalışma ve araştırmalar da çeşitlenerek artacaktır. Benzer çalışma yapacak araştırmacıların, araştırmaya katılım oranını yüksek tutmak için alternatif tedbirler alması uygun olur. Örneğin öğrencilerin bir kısmına kağıt tabanlı ölçek ulaştırılabilir. Farklı eğitim modellerinde (örgün, uzaktan ve harmanlanmış) eğitim alan öğrenci guruplarına uygulanarak karşılaştırmalar yapılabilir. Üniversiteler uzaktan eğitim altyapılarını oluştururken öğrencilerin tutum ve görüşlerine göre çalışmalar yapılabilir. Mobil teknolojilerin uzaktan eğitime yönelik tutumu olumlu yönde etkilediği göz önünde bulundurulacak olursa, öğrencilerin mobil teknolojilere (akıllı telefon, tablet bilgisayar vb.) erişim ve sahip olmaları için tedbirler alınabilir. Uzaktan eğitim verilecek programlara kayıt yaptıran öğrencilere bu teknolojiler uygun maliyetlerle temin edilebilir. Ücretsiz veya çok düşük ücretlerle internete erişim imkanları yerel ve ulusal projelerle sağlanabilir.

\section{Kaynakça}

Ateş, A., Altun, E., (2008). Bilgisayar Öğretmeni Adaylarının Uzaktan Eğitime Yönelik Tutumlarının Çeşitli Değişkenler Açısından İncelenmesi. Gü, Gazi Ĕ̆itim Fakültesi Dergisi,28(3), 125-145.

Birişçi, S. (2013). Video Konferans Tabanlı Uzaktan Eğitime İlişkin Öğrenci Tutumları ve Görüşleri. Journal of Instructional Technologies E Teacher Education, 1(2), 24-40. 
Büyüköztürk, Ş., Kılıç Çakmak, E., Akgün, Ö. E., Karadeniz, Ş. ve Demirel, F. (2012). Bilimsel Araştırma Yöntemleri (11. Baskı). Ankara: PegemA Yayıncılı.

Haznedar, Ö. ve Baran, B. (2012). Eğitim Fakültesi Öğrencileri İçin E-Öğrenmeye Yönelik Genel Bir Tutum Ölçeği Geliştirme Çalışması. Eğitim Teknolojisi Kuram ve Uygulama, 2(2), 42-59.

Kazu, İ.Y. ve Özdemir, O. (2002). Teknik Öğretmen Adaylarının Uzaktan Ĕ̆itimle İlgili Görüş Ve Beklentileri (Fırat Üniversitesi Örneği). XI. Eğitim Bilimleri Kongresi, Yakın Doğu Üniversitesi, Lefkoşa, KKTC.

Kışla, T. (2005). Üniversite Öğrencilerinin Uzaktan Ĕ̆itime Yönelik Tutumlarının İncelenmesi. Yüksek Lisans Tezi, Ege Üniversitesi, Sosyal Bilimler Enstitüsü.

Merisotis, J.P., Phipps R.A. (1999). What's the Difference?: Outcomes of Distance vs. Traditional classroom-based learning. Change: The Magazine of Higher Learning, 31(3), 12-17.

Özyurt, O. (2014). Clustering Analysis of Students' Attitudes Regarding Distance Education: Case of Karadeniz Technical University. Mevlana International Journal of Education (MIJE), 4(1), 113-122.

Özkul, A.E. ve Aydın, C. H. (2012), Öğrenci Adaylarının Açık ve Uzaktan Öğrenmeye Yönelik Görüşleri. Akademik Bilişim, 1-3, Şubat, Uşak Üniversitesi.

Powers, S.M. ve Mitchell, J. (1997). Student perceptions and performance in a virtual classroom environment. ERIC Document Reproduction Service No. ED 409005.

Sankaran, S.R., Sankaran D., and Bui T.X., (2000).Effect of Student Attitude to Course Format on Learning Performance:An Empirical Study in Web vs. Lecture Instruction. Journal of Instructional Psychology, 27(1), 66-73.

Smith, D.L. ve McNelis, M.J. (1993). Distance education: graduate student atttitudes and academic performance, ERIC Document Reproduction Service No. ED 360948.

TÜİK, (2014). Girişimlerde Bilişim Teknolojileri Kullanımı Araştırması, Hanelerde Bilişim Teknolojileri Kullanımı Araştırması (16-74 yaş arası bireyler). http://www.tuik.gov.tr/PreTablo.do?alt_id=1028 Erişim, 24.11.2014.

Yıldırım, S., Yıldırım, G., Çelik, E. ve Karaman S. (2014). Uzaktan Eğitim Öğrencilerinin Uzaktan Eğitime Yönelik Görüşleri: Bir Ölçek Geliştirme Çalışması. Ĕ̆itim ve Öğretim Araştırmaları Dergisi Journal of Research in Education and Teaching, 3(3), 365-370. 


\section{Extended Summary}

Distance education is a form of education in which information and communication technologies are used at the highest level. Analyzing the attitudes towards distance education of target groups from institutions which employ or will employ distance education, is greatly important both for defining the distance education vision of the institution and for being the source for the future studies on this subject.

This study is aimed at analysing the attitudes towards distance education, of the students who have education at Namık Kemal University Tekirdag Degirmenaltı Campus, according to different variables. The study group consist of 282 freshmen who study at Namı Kemal University Tekirdag Degirmenaltı Campus in 2013-2014. In the study, "The Scale of Attitudes Towards Distance Education " which is developed by Kışla (2005) is used. Data is collected by the Google survey tool which is delivered to the students through the Learning Management System (LMS) of Namik Kemal University. In comparison of the quantitative data, t-test is used to find the difference between two groups, in case of two or more groups, Oneway ANOVA is used to compare the parameters between groups and Scheffe test is used in determination of the group causing difference.

$58.5 \%$ of students were male and $41.5 \%$ of them were female who participated in the study. $79.4 \%$ of students has their own computer, $62.1 \%$ of the students have constant access to the internet, $56.7 \%$ stated that they have also have a smart phone or tablet computer.

As a result of the analysis performed to determine attitude scores of students who participated in the study whether to show a significant difference compared to the average faculty variables, Fine Arts, Design and Architecture Faculty students were seen to be higher attitude scores of students from other faculties or colleges attitude scores.

Total number of target audience of faculty, colleges and vocational schools while 2850 participating in this study, it was observed that 282 is the participation rate of approximately $10 \%$.

Despite the high rate of students' having computer, smart phone or tablet computer and constant access to the internet, low-level attitudes towards distance education may indicate that these students do not use the Internet and computers for educational purposes.

In conclusion, the attitude level of the participating students is detected as low. In terms of ownership of information technology has been shown to result in similar results emerge earlier studies. Accordingly, it is observed that the attitude points of those who have computers, continuous internet access possibility and mobile devices, have higher attitude points than those who have none of these, however, based on gender, there is no significant difference observed in the attitudes. 